\title{
Using analogies to explain versus inspire concepts
}

\author{
AMANDA CHOU AND L.H. SHU \\ Department of Mechanical and Industrial Engineering, University of Toronto, Toronto, Canada \\ (RECEIVED February 28, 2014; ACCEPTED December 8, 2014)
}

\begin{abstract}
We aim to examine the potential of using analogies in design education and to compare the roles of analogies in explaining versus inspiring in engineering design. We review existing research in analogical thinking, with a focus on scientific discourse and education. Then we explore the role of analogies in design education in making concepts more relatable by asking six participants in a graduate-level design course to generate analogies for course topics. We describe criteria developed to evaluate the analogies and present these evaluations. We then asked participants to perform divergent thinking tests, but we found no significant correlation between these and analogy scores. The participants were also asked to reflect on what constitutes an effective analog, describe their process of identifying analogies, and provide their definitions of analogies. We describe possible links between these comments and the ratings of their analogies. We then draw on results in using analogies in pedagogy to inform and reflect on obstacles we encountered in the use of analogies to inspire. Specifically, we related them to our experience with biomimetic or biologically inspired design, where we used a natural-language search approach to identify relevant analogies. Three aspects discussed are familiarity of source analogies, boundaries of parallels between source analogies and target concepts, and concreteness of source analogies. Finally, we discuss possible pedagogical benefits of eliciting analogies on course topics from students, namely, using the elicited analogies as tools for improved student engagement as well as more prompt instructor feedback.
\end{abstract}

Keywords: Analogies; Biologically Inspired Design; Design Education; Natural-Language Search Approach

\section{INTRODUCTION}

Analogies can be used to explain a foreign target concept through a more familiar source (or analog, anchor, base, and vehicle) concept by identifying similarities in structure and relationships. For design, source analogies are used to inspire target concepts. More generally, analogies represent a cognitive process whereby information from one concept is transferred to another. While our laboratory's experience has been in the use of analogies to inspire, we became interested in their use to explain (i.e., clarify concepts through detailed descriptions) and found that insights gained in the latter may inform our observations in the former. We begin with an overview of the study of analogies that focus on their role in explaining.

Analogical reasoning has played an important role in science, law, and even politics. For example, Harré (1988) stated that many analogies were used in explanations in medicine and physics. Holyoak and Thagard $(1995,1997)$ provide examples of analogy use in fields from psychotherapy to politics. Duit (1991), Clement (1993), and others reveal the potential in anal-

Reprint requests to: L.H. Shu, Department of Mechanical and Industrial Engineering, University of Toronto, 5 King's College Road, Toronto, ON M5S 3G8, Canada. E-mail: shu@mie.utoronto.ca ogies to familiarize abstract concepts by grounding them in real-world examples, provide visualizations, and even motivate students by connecting a foreign concept with a familiar, perhaps fun, idea. Duit and Treagust (2003) also note that analogies can lead to conceptual change learning, whereby the learner experiences a restructuring of preinstructional mental models, or understanding, to learn a new concept. Analogies have also played important roles in significant scientific advancements; Nersessian (2008) established that model-based reasoning, such as creating analogies, forms the basis for novel representations of concepts that push the development of science.

\subsection{Clarification of analogical expressions}

Below are brief definitions of analogical expressions that often appear in educational contexts and everyday speech. By themselves, these are informal vehicles for delivering analogical thought, and their use highlights pitfalls with careless use of analogies to explain.

\subsubsection{Metaphor versus simile}

Both metaphors and similes are considered analogical figures of speech. These terms are used more commonly in 
the arts than to describe formal mappings between scientific concepts. In the classroom, however, analogies are often phrased as these rhetorical figures of speech. Generally, metaphors assert that one thing is another, while similes highlight their similarity using "like" or "as." For example, "imagine that electricity is water flowing through a conduit," is a metaphor, while "electricity is like water flowing through a conduit" is a simile.

\subsubsection{Idioms}

An idiom is a combination of words with a figurative meaning that cannot be determined from the sum of the individual meanings of its constituents. For example, "spill the beans" means to let out a secret, which has nothing to do with spilling or beans. Many idioms are analogical, and mappings between the figurative meaning and literal statement can be constructed; for example, "beans" are like secrets, and when spilled, are difficult to clean up, like how a secret cannot be untold.

Unlike explicit formulation of analogies to explain a scientific concept, idioms are used as colloquialisms that the speaker or author expects the audience to know, much like any other word on its own. When uttering "spill the beans," the speaker is unlikely to explain the reference to secrets. Thus, the use of idioms assumes the audience already knows the mapping, or at least the intended figurative meaning. Such an assumption may be inappropriate in education, because explaining a foreign concept using an analog that the student does not understand makes little sense. Furthermore, both language skills and personal tendencies have significant effects on the appropriateness of idioms as effective communication; for example, the many engineers who study and work in a nonnative language, and are more literal in nature, may be particularly ill suited for idioms.

\subsection{Analogies and cognition}

At a cognitive level, some believe that analogies are an inherent way of thinking. Lakoff and Johnson (1980) argue that metaphors are a fundamental mechanism of the mind; concepts that govern our thought also govern our everyday functions, and the human conceptual system is largely metaphorical. Gentner (1989) suggests that in the processing of sensory information from external stimuli, the brain searches through analogical "bundles" for comprehension. In other words, what we know about something depends on everything else we know. Heywood (2002) also suggests that learning via analogies creates a deeper appreciation for knowledge, as it is rooted in socially constructed meaning as opposed to absolute "truth."

We note that analogies are a natural way to explain concepts. For example, when asked, "What is __?" we often say, "it is like ....," and perhaps add "but ..." or "however, ...."We root our understanding of things on other things, learn by building connections, and explain using connections between ideas.

\subsection{Analogies as hypotheses}

When two things share parallels in many aspects, there are likely to be further parallels (Gentner, 2002). However, while analogies can help elucidate a new concept, if similarities are extrapolated too far, understanding of the target can be compromised, or entirely wrong. In contrast, because the mapping between similar aspects of the concepts is symmetrical, the target concept often introduces a new perspective for the source concept. That is, we can learn more about the source through what we know about the target, and not just the other way around. Treagust et al. (1992) refer to this as the "two-way aspect" of analogies.

Many great figures in science and engineering attest to the value of analogical thinking in the discussion of new concepts. They conceptualize, communicate, and even advance their ideas and discoveries through analogies. Analogies can not only communicate and explain concepts but also identify structural similarities between domains and further scientific discovery by helping in forming hypotheses. In the discovery of a novel concept A, and its mapping to a similar analog concept $\mathrm{B}$, we can postulate that perhaps A shares more aspects of $\mathrm{B}$ beyond what we already know.

Podolefsky and Finkelstein (2006) note that James Clerk Maxwell (1885), a mathematical physicist best known for his equations on electromagnetism, applied mathematical ideas obtained from fluid mechanics to electrical science, and used analogies to generate physical hypotheses. Davies et al. (2005) present a detailed analysis of visual analogies used by Maxwell. By drawing potential additional parallels, Reynolds et al. (2004) constructed an algorithm to generate hypotheses based on structural mapping of analogies, leading to plausible hypotheses given sets of aligned structural statements.

Scientific advancement often comes from the investigation of these hypotheses. Theoretical physicist and Nobel laureate Richard Feynman argues that analogies enable physicists to maintain a broad knowledge despite numerous ongoing discoveries; many equations share analogous mathematical forms, indicating similarities between physical phenomena (Feynman et al., 1964). Stephen Hawking uses 74 analogies in A Brief History of Time (1988). Other analogies are Carnot's heat engines with waterfalls and Rutherford's planetary model of the atom (Karam \& Ricardo, 2011).

\subsection{Overview of paper}

The remainder of this paper is organized as follows. Section 2 reviews the use of analogies in science education. Section 3 presents an exploratory study on the role of analogies in design education. Section 4 draws on results in using analogies in pedagogy to inform and reflect on obstacles we encountered in the use of analogies to inspire. Section 5 identifies potential pedagogical benefits of eliciting analogies on course topics from students. 


\section{ANALOGIES IN SCIENCE EDUCATION}

In science, similes and metaphors help form the mental models necessary for students to understand new concepts (Solomon, 1986). Explanations often require references to nonobservable entities, which often rely on analogies (Harré, 1988).

\subsection{Classroom use of analogies}

Several researchers studied the use of analogies in the classroom. Clement (1993) analyzed student understanding of concepts taught using analogies, found a lack of care in choosing analogies to teach physical concepts, and suggested that a series of bridging analogies, each with smaller conceptual gaps, aids in explaining distant concepts. Clement also recommends interactive group discussions, as students often contribute creative examples and can evaluate whether the presented analogies make sense to them. Treagust et al. (1992) studied how teachers incorporate analogies into their class preparation and found, in a sample of 7 , that high school teachers used examples more than analogies, and some were unable to differentiate between the two. Analogies, when used, were often not used to their full potential (i.e., lacking in detail).

\subsection{Textbook use of analogies}

Noting that over half of the analogies found in textbooks are not explained, and many that are, are done with little depth, Duit (1991) suggests that guidance on analogies in textbooks is also needed, but often missing. Orgill and Bodner (2006) note that concrete analogies tend to be used to illustrate abstract concepts in biochemistry textbooks, for example, "the triple helix structure is similar to that of a rope" (Boyer, 1999). Concreteness can also refer to intangible, but familiar concepts. For example, "in the energy economy of a cell, glucose reserves are like ready cash" (Campbell, 1999) assumes a concrete grasp of the availability of cash versus other financial resources.

\subsection{Limitations of analogies in education}

Acknowledging that analogies break down once the conceptual similarities are exhausted, Gentner and Gentner (1983) note that certain analogies may be more relevant in explaining particular components of a new concept. For example, they found that to understand electric circuits, students using a "moving crowd" analogy understood the concept of resistors better, while those using a "flowing water" analogy understood the concept of batteries better. Thus, self-formed analogies, or mental models of how things work, can both inform and misguide students. If cognition is a bundle of analogies, the network of existing bundles will determine how new pockets of information will be incorporated within the students' larger mental models. Clement et al. (1989) found in a study that examples that experts deemed to be highly analogous to a given phenomenon were often not understood well by students. Students may have unasked questions, and make their own assumptions, extrapolating from the analogy. Harrison and Treagust (1996) found that high school science students often transferred attributes from the analog literally, and that analogical models can be dangerous when students are left to draw their own conclusions from them.

\subsection{Analogical models for education}

After Zeitoun's (1984) general model of analogy teaching, many others established their own frameworks, including Glynn's (1991) teaching with analogies model, designed to help guide teachers in using analogies in a systematic way. Both Zeitoun and Glynn recognized that care must be taken in the use of analogies in the classroom, and that limitations must be defined. Because the concepts are inherently different, Glynn confirms that all analogies break down somewhere, as the mapping is never exactly one-to-one. Thus, to avoid misinterpretation, nonshared attributes must be discussed. Glynn also recognizes that analogies should be chosen to accommodate different backgrounds to be familiar to many students, as analogies only work when rooted in existing knowledge (Glynn \& Muth, 1994).

\subsection{Analogies in design versus science education}

The study of analogies in science education appears focused on physical phenomena, where a nonobservable mechanism is explained using an analogous, observable mechanism. For example, to explain static normal force, Clement (1993) begins with a hand on a vertical spring to explain that a table can exert a normal force on a book resting on top. While it is easy to see that a spring can push back on an applied force, it is less obvious that a table can do the same.

Design methods relate more to humans than to fundamental laws, but analogies can improve accessibility of a concept, method, or guideline by relating it to ideas familiar to students. Analogies can also reveal higher order relations that allow students to extend concepts beyond the domain of design. Because many concepts taught in design education are mental tools and guides, we believe that by providing a broader analogical context for a course concept, design tools can be more effectively and readily understood, recalled, and used by students.

\section{EXPLORING THE ROLE OF ANALOGIES IN DESIGN EDUCATION}

In light of the above insights, we wanted to explore the role of analogies in design education by conducting a series of classroom experiments. The participants were six master's students (two female, four male) in a graduate-level course on creativity in conceptual design offered by the Department of Mechanical and Industrial Engineering at the University of Toronto. Of the six students, five had backgrounds in mechanical engineering, 
Table 1. Rubric for scoring analogies generated on course concepts

\begin{tabular}{|c|c|c|c|c|}
\hline & 1 & 2 & 3 & 4 \\
\hline Logic & $\begin{array}{l}\text { No logical relationship between } \\
\text { concept and proposed } \\
\text { analog, or not factual }\end{array}$ & $\begin{array}{l}\text { Flawed logic or lacking in } \\
\text { factuality }\end{array}$ & $\begin{array}{l}\text { Logical, but focuses on an } \\
\text { unimportant aspect of } \\
\text { concept, or covers concept } \\
\text { imprecisely }\end{array}$ & $\begin{array}{l}\text { Mapping is logical and focused } \\
\text { on the } \operatorname{aspect}(\mathrm{s}) \text { of concept; } \\
\text { factual }\end{array}$ \\
\hline Clarity & $\begin{array}{l}\text { Vague or overly complex, } \\
\text { unsure what analogical } \\
\text { relationship is implied }\end{array}$ & $\begin{array}{l}\text { Takes some effort to } \\
\text { understand, but still unclear }\end{array}$ & $\begin{array}{l}\text { Can understand analogy, but } \\
\text { could be more clear }\end{array}$ & $\begin{array}{l}\text { Can immediately see } \\
\text { relationship, requiring low } \\
\text { effort to understand }\end{array}$ \\
\hline Domain & $\begin{array}{l}\text { Too literal, not an analogy, just } \\
\text { an example }\end{array}$ & $\begin{array}{l}\text { Beyond an example, but overly } \\
\text { similar to source domain }\end{array}$ & $\begin{array}{l}\text { Domain is distinct but not } \\
\text { inspiring or interesting }\end{array}$ & $\begin{array}{l}\text { Domain is distant enough to } \\
\text { inspire a different } \\
\text { perspective, or help with } \\
\text { understanding }\end{array}$ \\
\hline
\end{tabular}

and one had a background in civil and environmental engineering. Two were working full time while pursuing course-based master's degrees part time, two were pursing research-based master's degrees, and the remaining two were pursuing course-based degrees as full-time students.

\subsection{Eliciting cross-domain analogies for course concepts}

We asked students to write down and submit cross-domain analogies for the main concept taught, at the end of each lecture. Most students generated only one analogy per concept, and generally took 5-10 min. After noting that many of the first set of analogies addressed limited aspects of a concept, we asked participants to identify analogies that support the benefit of a method, approach, or guideline, for example, the benefit of generating several concepts early in the design process. Later, we also asked for analogies that reveal the limitations of concepts, for example, lead-user methods. These analogies were then discussed in the subsequent lecture. Appendix A shows examples of "good" analogies for each of 10 course topics.

\subsection{Rating analogies}

We developed a rubric of three criteria, each with four levels, shown in Table 1. Logic addresses whether the structural relationships in the proposed analogy match the concept. It also includes factuality, as we noticed that some statements about biological analogies were inaccurate. Clarity addresses the quality of communication. Because we received the responses in written form, vagueness and overly brief or convoluted statements compromised raters' understanding. Finally, domain addresses whether the analogy reveals a different perspective, or is a literal example. For example, to support the benefit of modular architecture, one participant wrote about site trailers that could be connected together, which was deemed a same-domain example.

Our criteria for assessing analogies for design course concepts differ from those suggested by Gentner (1982) for scientific analogies. Detailed structural mapping is emphasized in explanatory analogies for scientific concepts, but we emphasize the ease of seeing a connection between the domains. This is closer to what Gentner (1982) refers to as expressive analogies.

\subsection{Results and examples of rating analogies}

Two raters independently scored all 118 analogies generated for 10 course concepts. We computed the Cohen $\kappa$, a statistical measure of interrater agreement for categorical ratings, and achieved a "moderate" level of agreement (Landis \& Koch, 1977) for all three criteria: $\kappa_{\operatorname{logic}}=0.53, \kappa_{\text {clarity }}=$ 0.47 , and $\kappa_{\text {domain }}=0.45$. We found responses had to perform well (score 3-4) in all three criteria to correspond to an intuitively good analogy; for example, a clearly explained response with poor logic and distinct domain is still ineffective. Examples follow.

1. Example of a 444-rated analogy (for need identification methods):

River flow measurement $\rightarrow$ use of various methods $\rightarrow$ standing in river with flowmeter and taking care to stand far enough away so as not to interfere flow, but could be some interference still; launching a "free" flowing device and measuring/receiving telemetry from outside the river.

2. Example of a 141-rated analogy (for modular architecture) clear, but not an analogy:

If one part breaks down, just replace that one part instead of whole thing, e.g., car parts, tennis strings vs. getting new racquet

3. Example of 323-rated analogy (for functional decomposition), unclear mapping of function/needs:

A family who wants to move to a new location. First, they have to identify what the functions (needs) of the family members such as education, recreation, work. And decomposing the functions (needs) to specify the details such as what type of school? To help the family decide what locations have the best functions \& characteristics for the family to move into. 
Table 2. Mean analogy scores and standard deviations for all six participants

\begin{tabular}{|c|c|c|c|c|c|c|c|c|c|}
\hline Participant & Logic & Clarity & Domain & Avg. & Participant & Logic & Clarity & Domain & Avg. \\
\hline \multicolumn{10}{|l|}{1} \\
\hline Mean & 3.00 & 3.15 & 3.15 & 3.10 & 4 & 2.12 & 2.15 & 2.61 & 2.29 \\
\hline$S D$ & 0.50 & 0.67 & 0.78 & & & 0.91 & 0.99 & 0.81 & \\
\hline \multicolumn{10}{|l|}{2} \\
\hline Mean & 2.73 & 2.82 & 3.55 & 3.03 & 5 & 2.86 & 2.73 & 2.82 & 2.80 \\
\hline$S D$ & 0.86 & 1.03 & 0.66 & & & 0.98 & 1.01 & 0.75 & \\
\hline \multicolumn{10}{|l|}{3} \\
\hline Mean & 3.50 & 3.41 & 3.36 & 3.42 & 6 & 2.32 & 2.26 & 3.00 & 2.53 \\
\hline$S D$ & 0.64 & 0.63 & 0.71 & & & 0.98 & 0.94 & 0.73 & \\
\hline
\end{tabular}

Table 2 provides each participant's scores for each criterion averaged over all the participant's analogies, the standard deviations, and the average score for the three criteria.

We noticed that participants were fairly consistent in their exhibited approach. Analogies that were rated higher, where the analogical components were clearly outlined and structural mappings were logical, tended to consistently come from the same participants. Other participants tended to generate vague analogies, capturing the concepts only minimally. We note that Participant 3 scored well consistently, while Participant 4 performed poorly, but produced 5.8 analogies per concept on average. All other participants typically produced one or two responses, with Participant 6 occasionally producing three responses per concept/topic.

\subsection{Discussion of elicited analogies}

In generating analogies for "affordances," two students described medicinal side effects to express that affordances of a product may not have been intended by the designer. Participant 3's analogy below may help students appreciate the potential severity of consequences arising from disregarding affordances in design. However, the analogy also clarifies the limitations of affordances; while side effects can take over the main purpose of the drug, as is the case with Viagra ${ }^{\mathrm{TM}}$, affordances cannot overtake the main functions of a product.

Affordances are like ... side-effects when designing pharmaceutical drugs. E.g., Bayer researchers designed aspirin and heroin to fulfill the function of painkilling but the unintended side-effects of heroin led to it becoming an addictive recreational drug. Therefore identifying affordances is important in preventing unintentional harm to users (or leading to unethical benefits for the company by getting users addicted).

Highly rated analogies were often presented in a structured manner, with analogous components mapped explicitly. For example, in the last sentence of the below, Participant 3 maps form to function, suggesting that explicit mapping could create better analogies in analogy generation.
The benefit of identifying/decomposing functions in a football analogy would be the coach organizing and planning strategies with the attackers and defenders on the team to achieve those objectives. For example, the positioning of the defenders would be the "form" to achieve the "function" of preventing opponents scoring.

In participant comments on what makes analogies effective (Appendix B), students mention personally relatable ideas, as well as low effort in understanding. This corresponds well with our evaluation criteria, which addresses ease of understanding. Gick and Holyoak (1983) noted that analogies not familiar to students become an extra burden to learn and fail to explain or describe.

\subsection{Tests of divergent thinking}

We next conducted creativity tests to see whether their results could be correlated with quality of analogies generated. While logical reasoning (often measured as IQ) is required for analogical correctness, generating analogies is also a divergent thinking task involving creativity. The domains from which analogies can be drawn are theoretically unlimited. Thus, we postulate that those with higher quality analogies may score higher on divergent thinking tasks.

Guilford (1967) suggests the following measures for creativity: fluency (number of responses); flexibility (number of response categories); originality (number of unique responses); and elaboration (level of detail of responses).

We sought to examine whether creativity scores between tasks involving simple, everyday ideas align with creativity scores in analogical generation, and whether these scores could indicate high-quality analogies. Because we elicited the analogies with minimal prompt (only asked participants to generate analogies for a given topic), we can apply these same measures to the responses. However, simpler, universally familiar creativity exercises, for example, generate drawings using circles as prompts, may have fewer constraints. Therefore, the reduction in number or range of ideas in analogy generation tasks could be due to fewer viable ideas.

To avoid bias toward particular problem domains and favoring students familiar with those domains, the Guilford 
tests were performed using open-ended questions with loose restrictions. The Miller Analogies Test and Remote Associates Test (Mednick, 1963) were also considered, but they were deemed overly dependent on participant vocabulary size.

Tasks asked of participants are as follows, where parenthesized information was not provided as text, but describes the worksheets that were provided.

- Use the (grid of four columns by five rows of) circles as prompts for drawing. Each circle is used in a separate drawing. Draw for 5 min.

- Use the (grid of four columns by five rows of) triangles as prompts for drawing. Each triangle is used in a separate drawing. Draw for $5 \mathrm{~min}$.

- Name as many uses for a binder clip as you can think of in $5 \mathrm{~min}$. Use bullet points.

- Name as many uses for a candle as you can think of in 5 min. Use bullet points.

\subsection{Results}

Below, we discuss the results of comparing creativity measures and analogy generation.

\subsubsection{Fluency}

Fluency, or number of responses, is the most objective of Guilford's suggested creativity measures. We compare average fluency values for analogy generation, alternative uses, and shape-prompted drawings. Spearman's rank correlations for each pair are shown in Table 3.

Table 3 shows that only fluency between listing alternative uses and drawing are highly correlated and statistically significant. This suggests that with unrestrictive creative activities, the relative volume of ideas produced by participants is more consistent, regardless of whether the task is verbal or visual. With analogy generation, the extra constraints and logical analyses required of the task may reduce the number of analogies produced.

\subsubsection{Originality and flexibility in alternative uses test}

We quantify originality only for the alternative uses test. Generated analogies were almost always drawn from different domains, as were shape-prompted drawings, which were not restrictive enough to cause many overlaps in ideas between

Table 3. Spearman's correlations for fluency between analogy generation and creativity tasks

\begin{tabular}{lcc}
\hline \hline & $\rho$ & $p$ \\
\hline Analogy/uses & 0.46 & 0.181 \\
Analogy/draw & 0.39 & 0.225 \\
Uses/draw & 0.90 & 0.007 \\
& & \\
\hline
\end{tabular}

participants. Alternative uses, in contrast, had several common as well as unique responses. Two raters identified all unique responses for all participants, with uniqueness defined as inversely proportional to frequency of occurrence in the sample. Interrater agreement was measured using the Cohen $\kappa(\kappa=0.44)$, which, according to Landis and Koch (1977), is a qualitative "moderate agreement."

The same two raters measured flexibility for the alternative uses test. Each rater developed a set of categories for the entire set of responses, and enumerated the categories appearing in each participant's answer. The Pearson correlation coefficient of the flexibility scores given by each rater is $\rho=0.95$. The results of the drawing exercise are discussed anecdotally below.

\subsubsection{Analogy generation versus creativity tests}

We next examined our data by comparing analogy generation to creativity test results. With six participants, we only suggest qualitative trends.

Alternative-uses tasks. Alternative uses often had varying specificity, which resulted in overlaps in listed uses. For example, for uses of candles, one participant listed "burn," "warmth," and "melt plastic," so there is at least one overlap as "burn" refers to either burning of the candle itself (warmth) or use of the candle to burn another object (melt plastic). We did not take this into account in the scoring; while overlaps may be accounted for in low elaboration scores (because detail in responses will reduce likelihood of overlap), alternative uses results were of similar elaboration levels. We noted that all participants produced more uses for a candle than a binder clip, perhaps due to its ease of phase change, and having more common everyday uses (e.g., birthday cakes are mentioned by all but one participant).

Drawing tasks. For the drawing questions, there were also no distinct differences between degrees of elaboration, except possibly by Participant 5. Elaboration and fluency appear to come at the cost of originality and flexibility, and ideas often follow the same theme, such as sports, food, or nature. There were no obvious differences in fluency between the problem types, and the number of responses may indicate the approach participants take in tackling problems.

Participant 3. Participant 3 consistently produced highquality analogies in class, and scored second highest in fluency for alternative uses, though notably low in flexibility. In the drawing questions, although not following the provided instructions, this participant demonstrated creative use by incorporating multiple circles in two of the drawings. Participant 6 was the only other one who used more than one shape per drawing, though in a much more abstract manner. Participant 3 is also noted for high flexibility in analogy generation, covering topics such as river flow, pharmaceutics, and football. However, it remains unclear whether the ability to generate spontaneous ideas given few restrictions correlates with generating good analogies. 
Participant 4. Of note, Participant 4 consistently produced the most responses for the drawing tasks. However, this participant's responses were also consistently unelaborated, and exhibited low flexibility in both analogy generation and drawing questions, gathering ideas from a limited range of topics. The participant admitted later to the belief that all shapes must be filled for the drawing questions, though this was not indicated in the problem statement. In the alternative user test, Participant 4 was flexible and obtained the highest creativity quotient score (Snyder et al., 2004). This is consistent with Kudrowitz and Dippo (2013), who identified that those with more responses tended to also have more novel responses. Participant 4 also mentioned after the test that a previous course on innovative product design provided exposure to insightful uses of a candle.

Kudrowitz and Dippo (2013) noted that novel ideas tended to arise after the first nine responses in the alternative uses test. However, we did not see this in our limited sample size, even though our participants were given 5 min for each alternative uses test, versus 3 min in their study.

\subsubsection{Analogy generation versus definitions of analogy and processes to identify analogies}

Finally, we asked participants to provide definitions of analogies as well as describe the process they underwent when identifying analogies. Appendix B contains excerpts of responses. In hindsight, we believe that these responses may explain the difference in the ratings of analogies. For example, the lowest-rated analogies were generated by those who characterize the process as "random" (Participants 4 and 6 average scores $=2.29$ and 2.53). Next lowest-rated analogies came from those who emphasized the importance of "emotion," that is, emotional compellingness, in an analogy (Participants 5 and 2 average scores $=2.80$ and 3.03). Highest scores were 3.42 and 3.10 (Participants 3 and 1). All scores are out of 4.00 .

\section{APPLYING INSIGHTS TO USE OF ANALOGY TO INSPIRE}

By examining studies on the use of analogies in education, we identify insights that may explain obstacles in the application of analogies in biomimetic design. We refer to our experience with biological analogies retrieved through our natural-language search tool (Shu, 2010), developed to aid engineers in generating design solutions. We compare the use of analogies in the classroom for purposes of explaining a new concept with the mapping of biological phenomena to some engineering problem and solution domain.

\subsection{The analogy must be understandable (if not familiar)}

Many works attempting to identify teaching strategies to ensure effective use of analogies, for example, the TeachingWith-Analogies model, suggest that the analog concept used to explain should be a familiar one. Dagher and Cossman
(1992) refer only to analogies as the part of explanatory discourse where the familiar is used to explain the unfamiliar.

In biomimetic design, the biological analogies that inspire the most are likely to be unfamiliar to the designer, yet we informally observed that both novice and expert designers are biased toward familiar analogies. In practice, we believe that designers would be quite familiar with the problem with which they are tasked before they start looking for sources of inspiration in biology or elsewhere. However, given likely limitations in the designer's knowledge of analogous phenomena, the bias toward familiarity, in both source and target domains, may limit opportunity for inspiration. Specifically, we have long argued that designers should look beyond the scales or organization levels in biology with which they are most familiar, that is, from organ (e.g., heart, lung, or hand) to organism (e.g., specific animal or plant), and can most readily be observed casually (Shu et al., 2011). In addition, we observed that even expert designers tend to match novel analogies to existing and known solutions, rather than develop new solutions. We note that in our past experiments (Cheong \& Shu, 2013b), where novice designers were asked to generate design concepts given an engineering problem and a biological phenomenon, both concepts were presented as new information. Thus, mapping was perhaps more difficult in these experiments as opposed to a setting where the designer can seek alternative sources to better understand the concepts prior to mapping. In addition, novice designers tended to fixate on specific words within the stimulus text, particularly familiar words, for example, "motor" of "motor protein," and develop nonanalogous solutions, for example, those that incorporate motors (Shu et al., 2011).

Therefore, the question remains: how do we nudge designers away from the natural bias for the familiar, and toward analogies in the form of unfamiliar phenomena that may serve to inspire more? Similarly, how do we nudge designers toward developing new solutions from unfamiliar analogies, rather than mapping them to known solutions?

Researchers in biologically inspired design are working toward answering the first question by recognizing the difficulty engineers may have in understanding biological analogies and making the analogies as clear as possible, through pictures, diagrams, and so forth (Goel et al., 2014).

\subsection{Limits of analogy should be defined}

Models for systematizing analogy use in classrooms also suggest that the limits of the analogical boundary should be made clear to the student. Specific to written analogies, Glynn and Takahashi (1998) note that explicit mapping of the analog and target concepts must be made, in addition to explicit statements of limits of the analogy and conclusions that can be drawn in the target domain. In our classroom experiment, we separately sought analogies that support a concept, as well as demonstrate limitations of the concept. Experiment participants found value in this process, as well as in discussing the merits and limitations of example analogies they generated. 
Two different concepts cannot have a complete one-to-one mapping: inevitably, the analogy breaks down beyond the shared parallels. In other words, there must be extraneous aspects of each concept that do not map to the other. This can lead to students extrapolating parallels where they do not exist, which can misguide their understanding of the target concept.

Again, this is problematic when designers are provided a biological analogy for use to solve an engineering problem. In a previous study (Cheong et al., 2014), senior undergraduate engineering students were asked to design a credit card marketing solution using the pheromone release of ants as an analogy. Some students continued to draw parallels between the analogy and problem by stating that the queen ant was analogous to the CEO of the credit card company. This is an example of an unnecessary parallel because it does not contribute to the design solution, and the queen ant was not mentioned in the description of the biological phenomenon provided.

We note, however, analogical mappings to inspire are inherently open-ended, as designers must extrapolate from the biological phenomenon to their design solution by first identifying parallels between the domains. Because they may draw from multiple source analogies, extraneous information adds to the complexity of the task. In other words, there may be aspects of the biological phenomenon that have no appropriate parallel in the design problem, but will be tempting to draw. Goel (2012) notes that rerepresentation (e.g., rephrasing of text) of the domains is often necessary for an analogy to become obvious. This further adds to the difficulty in drawing analogies for design inspiration. Helms et al. (2009) also found that novice designers tend to fixate on biological features not analogous to the problem.

Designers may benefit from further researching the retrieved biological phenomenon in order to better understand its mechanisms prior to mapping. That is, designers may need to actively identify where the analogies break down to avoid fixating on irrelevant attributes of the phenomenon. In our laboratory, Cheong and Shu (2013b) developed templates to support the mapping of relevant attributes of source and target domains. Perhaps support, for example, guidelines, in identifying irrelevant attributes, could also be developed and provided in addition to those to identify relevant attributes.

\subsection{Concrete examples work best}

Concrete source analogies seem to be favored in explaining complicated ideas. Lemke (1990) suggests that science teachers attempt to humanize science by associating it with social processes in order to aid student understanding. Biochemistry textbooks mainly use concrete analogies to inform abstract concepts (Orgill \& Bodner, 2006), for example, glove and hand for enzyme and substrate. After analyzing several hundred science textbooks and comparing the relative levels of abstraction between the source and target concepts, Orgill and Bodner noted that analogies tend to be used in cases where the target material is difficult or abstract. While most target concepts are abstract, most analogs used to explain are concrete in nature, which are easier to understand (Curtis \& Reigeluth, 1984; Thiele \& Treagust, 1994).

The preference for concreteness over abstraction is supported by our observation of many challenges encountered by novice designers when asked to map a biological phenomenon to an engineering problem. Cheong and Shu (2013b) substituted biological nouns with more abstract nouns, for example, "blood" with "fluid," in text descriptions to reduce fixation and bias when selecting and mapping biological analogies. However, this intervention did not improve the quality of mappings between the biological phenomena and the engineering solutions. We now see that in eliminating the possibility of designers using previous knowledge of biological concepts, we also eliminate any possible familiarity with the notions. The concepts become more difficult for designers to both understand and map, which was confirmed to statistical significance (Feng et al., 2014). In essence, abstraction forces the designer to use only the remaining information available to create analogies. While this may be a helpful exercise for analogical thinking, it is generally unheard of in educational contexts.

However, Gentner and Jeziorski (1989) identify analogies as relational commonalities between entities, which are independent of the attributes of the objects holding the relation. In the solar system versus atom example, we note that the hotness of the sun is irrelevant to the relationships between the analogous components. In this sense, abstracting nouns (e.g., sun) to prevent designers from incorporating irrelevant information (e.g., hotness) makes sense. Table 4 summarizes insights from use of analogy to explain, to the use of analogy to inspire.

\section{CONCLUSION}

A study of analogies in education provided us with another perspective on the challenges we observed in designers when using biological phenomena as design stimuli. In Table 4, we identify three recurring points in use of analogies for both explaining and inspiring, particularly for novices: use concrete analog concepts that are easy to picture, identify boundaries at which the analogy breaks down, and use understandable if not familiar analog concepts.

We note that designers may have to learn more about the retrieved biological phenomenon to first gain a better grasp of the mechanism itself, before trying to map it to the design problem. The designer must become familiar with both the design problem and the stimulus. That is, rather than attempt to reduce fixation on familiar analogies, or familiar words in the description of biological phenomena (as we have attempted), we should instead ensure that all relevant analogies are as understandable as possible, which is no minor feat. We have not been able to implement automated solutions that outperform Google and Google Images to aid in understanding of biological phenomena. However, these extra steps may 
Table 4. Comparison between analogy use in pedagogy and as design inspiration

\begin{tabular}{|c|c|}
\hline Teaching/Explaining & Inspiring in Biomimetic Design \\
\hline $\begin{array}{l}\text { Familiar: Use of familiar examples in teaching simplifies the } \\
\text { explanation process by relying on students' existing mental maps. }\end{array}$ & $\begin{array}{l}\text { Unfamiliar: Unfamiliar source analogies represent novel stimuli for concept } \\
\text { generation. Yet designers, as humans, may be drawn to the familiar when } \\
\text { selecting analogies. }\end{array}$ \\
\hline $\begin{array}{l}\text { Defined limits: In science teaching, limits of the analogies should be } \\
\text { explicitly defined to avoid erroneous extrapolation between the two } \\
\text { concepts. }\end{array}$ & $\begin{array}{l}\text { Open-ended: Designers are expected to extrapolate solutions after drawing } \\
\text { parallels between biological and design problem domains. The designer must } \\
\text { identify feasible mappings, given that the design problem may have aspects } \\
\text { unaddressed by the biological phenomenon and that it can be tempting to } \\
\text { draw poor analogies. }\end{array}$ \\
\hline $\begin{array}{l}\text { Concrete: By grounding new, target concepts to be taught in concrete } \\
\text { source concepts, students can draw from their own understanding. }\end{array}$ & $\begin{array}{l}\text { Abstract: Abstraction of biological phenomena, aimed to reduce bias and } \\
\text { fixation in their selection and mapping, resulted in reduced understanding of } \\
\text { the analogy instead. }\end{array}$ \\
\hline
\end{tabular}

be obstacle enough to direct designers to the most familiar, rather than the most useful or novel, analogies.

In our small study of analogy generation and divergent thinking in a graduate-level design class, we noticed that some students consistently produced high-quality, logical analogies, while others consistently produced lower quality analogies. We sought to examine the relationship between divergent thinking tasks and analogy generation by administering drawing exercises and alternative uses tests. We found a high, significant correlation between fluencies in drawing and alternative uses listing, but neither correlated with analogy generation. In hindsight, we believe that how a participant defines analogies and approaches the process of generating analogies may have a larger effect on the quality of his or her analogies. Longitudinal studies with a larger sample may allow us to identify and assess ways to improve analogical generation and reasoning.

\subsection{Pedagogical benefits of eliciting analogies on course topics}

While we did not obtain statistically significant results in our exploratory study of analogies in teaching, we did notice some unexpected benefits of eliciting analogies on course topics.

\subsubsection{Analogy as feedback for instructor}

Due to the small sample size, we did not formally compare the participants' class scores with their analogy scores. However, we did find that Participants 3 and 4 tied for the highest class scores but performed, respectively, the best and the worst in analogy generation. Prince and Felder (2006) note that traditional engineering methods are deductive, where examples are used to illustrate general concepts, but inductive teaching is at least as, if not more, effective. Thus, we postulate that engineering students such as our participants may be accustomed to deductive teaching and evaluation methods, which may result in course grades being poor predictors for analogy generation skills.
However, poor analogies generated by all participants could indicate an unclear lecture. For example, analogies elicited for fixation revealed a common confusion between fixation and other cognitive biases, and led to an additional unscheduled lecture on cognitive biases. The elicitation of analogies for a lecture topic to be discussed in the following lecture may provide feedback to the instructor more promptly than more formal assessment exercises.

\subsubsection{Analogy as engagement tool}

Analogies can serve as engagement tools by linking concepts to ideas or activities students find interesting or enjoyable. For example, we previously observed positive student responses to sports analogies, for example, "design fixation is like skating with one's head down in hockey," and "not learning multiple methods for the same task is like playing tennis with only a forehand." Because interest differs between students, inclusiveness becomes an issue. For example, the use of sports analogies likely works better with athletic or sports-minded students. Nonetheless, analogies catering to student interests may function beyond explanation, serving to inspire interest in topics pertaining to science and engineering. One benefit of eliciting analogies from students, which are subsequently discussed in class, is that such analogies are personal to the students and may enable inclusion that is difficult to achieve with preselected analogies. For example, an analogy for lead-user methods suggesting that Ramadan (a period of fasting) can serve to inform how dieters can lose weight was quickly rebutted by others familiar with the religious practice.

In an end-of-term debriefing session, the participants identified additional benefits of identifying analogies for course topics. Multiple students expected that they would find the course concepts taught to be more memorable because they would recall their own as well as their peers' analogies. Several students found that the process of identifying analogies became easier over time, and they reported their experience with analogies in teaching to be positive. Therefore, we will investigate how to incorporate the use of analogies in other courses with more participants. 


\section{ACKNOWLEDGMENTS}

The authors thank the participants of the study and the Natural Sciences and Engineering Research Council of Canada. This study was approved by the University of Toronto Ethics Review Board (Protocol Reference No. 30303).

\section{REFERENCES}

Boyer, R. (1999). Concepts in Biochemistry. Pacific Grove, CA: Brooks/ Cole.

Campbell, M.K. (1999). Biochemistry, 3rd ed. Orlando, FL: Harcourt Brace.

Cheong, H., Hallihan, G.M., \& Shu, L.H. (2014). Design problem solving with biological analogies: a verbal protocol study. Artificial Intelligence for Engineering Design, Analysis and Manufacturing 28(1), 27-47.

Cheong, H., \& Shu, L.H. (2013a). Reducing cognitive bias in biomimetic design by abstracting nouns. CIRP Annals 62(1), 111-114.

Cheong, H., \& Shu, L.H. (2013b). Using templates and mapping strategies to support analogical transfer in biomimetic design. Design Studies 34(6), $706-728$.

Clement, J. (1993). Using bridging analogies and anchoring intuitions to deal with students' preconceptions in physics. Journal of Research in Science Teaching 30(10), 1241-1257.

Clement, J., Brown, D., \& Zietsman, A. (1989). Not all preconceptions are misconceptions: finding anchoring conceptions for grounding instruction on students' intuitions. International Journal of Science Education 11, $554-565$.

Curtis, R., \& Reigeluth, C. (1984). The use of analogies in written text. Instructional Science 13, 99-117.

Dagher, Z., \& Cossman, G. (1992). Verbal explanations given by science teachers: their nature and implications. Journal of Research in Science Teaching 29(4), 361-374.

Davies, J., Nersessian, N., \& Goel, A. (2005). Visual models in analogical problem solving. Foundations of Science 10(1), 133-152.

Duit, R. (1991). The role of analogies and metaphors in learning science. Science Education 75(6), 649-672.

Duit, R., \& Treagust, D. (2003). Conceptual change: a powerful framework for improving science teaching and learning. International Journal of Science Education 25(6), 671-688.

Feng, T., Cheong, H., \& Shu, L.H. (2014). Effects of abstraction on selecting relevant biological phenomena for biomimetic design. Journal of Mechanical Design 136(11), 111111.

Feynman, R.P., Leighton, R.B., \& Sands, M. (1964). The Feynman Lectures on Physics, Vol. 2. Reading, MA: Addison-Wesley.

Gentner, D. (1982). Are scientific analogies metaphors? In Metaphor: Problems and Perspectives (Miall, D.S., Ed.), pp. 106-132. Brighton: Harvester Press.

Gentner, D. (1989). The mechanisms of analogical learning. In Similarity and Analogical Reasoning (Vosniadou, S., \& Ortony, A., Eds.), pp. 199-241. London: Cambridge University Press.

Gentner, D. (2002). Psychology of Analogical Reasoning. Encyclopedia of Cognitive Science. London: Nature Publishing Group.

Gentner, D., \& Gentner, D.R. (1983). Flowing waters or teeming crowds: mental models of electricity. In Mental Models (Gentner, D., \& Stevens, A., Eds.). Mahwah, NJ: Erlbaum.

Gentner, D., \& Jeziorski, M. (1989). Historical shifts in the use of analogy in science. In Psychology of Science: Contributions to Metascience (Gholson, B.W., Shadish, R., Neimeyer, R., \& Houts, A., Eds.), pp. 296-325. New York: Cambridge University Press.

Gick, M.L., \& Holyoak, K.J. (1983). Schema induction and analogical transfer. Cognitive Psychology 15(1), 1-38.

Glynn, S.M. (1991). Explaining science concepts: a teaching-with-analogies model. In The Psychology of Learning Science (Glnn, S.R., \& Britton, B., Eds.), pp. 219-240. Hillsdale, NJ: Erlbaum.

Glynn, S.M., \& Muth, K.D. (1994). Reading and writing to learn science: achieving scientific literacy. Journal of Research in Science Teaching 31(9), 1057-1073.

Glynn, S.M., \& Takahashi, T. (1998). Learning from analogy-enhanced science text. Journal of Research in Science Teaching 35(10), 1129-1149.

Goel, A.K., McAdams, D.A., \& Stone, R.B. (Eds.). (2014). Biologically Inspired Design: Computational Methods and Tools. London: SpringerVerlag.
Goel, A.K., Vattam, S., Wiltgen, B., \& Helms, M. (2012). Cognitive, collaborative, conceptual and creative-our characteristics of the next generation of knowledge-based CAD systems: a study in biologically inspired design. Computer-Aided Design 44(10), 879.

Guilford, J.P. (1967). The Nature of Human Intelligence. New York: McGraw-Hill.

Harré, R. (1988). Modes of explanation. In Contemporary Science and Natural Explanation: Common-Sense Conceptions of Causality (Hilton, D.J., Ed.). New York: New York University Press.

Harrison, A., \& Treagust, D. (1996). Secondary students' mental models of atoms and molecules: implications for teaching chemistry. Science Education 80(5), 509-534.

Hawking, S. (1988). A Brief History of Time. New York: Bantam Books.

Helms, M., Vattam, S., \& Goel, A. (2009). Biologically inspired design: process and products. Design Studies 30(5), 606-622.

Heywood, D. (2002). The place of analogies in science education. Cam bridge Journal of Education 32(2), 233-247.

Holyoak, K.J., \& Thagard, P.R. (1995). Mental Leaps: Analogy in Creative Thought. Cambridge, MA: MIT Press.

Holyoak, K. J. \& Thagard, P. (1997). The analogical mind. American Psychologist 52(1), 35-44.

Karam, R., \& Ricardo, E.C. (2011). Formal analogies in physics teacher education. Proc. Int. ESERA Conf. 2011, Lyon, France.

Kudrowitz, B., \& Dippo, C. (2013). Getting to novel ideas: exploring the alternative uses test of divergent thinking. Proc. ASME IDETC/CIE, Paper No. DETC2013-13262, Portland, OR.

Lakoff, G., \& Johnson, M. (1980). Metaphors We Live By. Chicago: University of Chicago Press.

Landis, J.R., \& Koch, G.G. (1977). The measurement of observer agreement for categorical data. Biometrics 33(1), 159-174.

Lemke, J. (1990). Talking Science. Norwood, NJ: Ablex.

Maxwell, J.C. (1885). Abstract of paper “On Faraday's Lines of Force.” In The Scientific Papers of James Clerk Maxwell (Niven, W.D., Ed.), pp. 367-369. Cambridge: Cambridge University Press.

Mednick, M.T. (1963). Research creativity in psychology graduate students Journal of Consulting Psychology 27(3), 265-266.

Nersessian, N.J. (2008). Creating Scientific Concepts. Cambridge, MA: MIT Press.

Orgill, M., \& Bodner, G.M. (2006). An analysis of the effectiveness of analogy use in college-level biochemistry textbooks. Journal of Research in Science Teaching 43(10), 1040-1060.

Podolefsky, N.S. \& Finkelstein, N.D. (2006). The use of analogy in learning physics: the role of representations. Physical Review ST: Physics Education Research 2(2), 020101.

Prince, M.J., \& Felder, R.M. (2006). Inductive teaching and learning methods: descriptions, comparisons, and research bases. Journal of Engineering Education 95(2), 123-138.

Reynolds, J., Pease, A., \& Li, J. (2004). Analogy and deduction for knowledge discovery. Proc. IEEE 2004 Int. Conf. Information and Knowledge Engineering, Las Vegas, NV.

Shu, L.H. (2010). A natural-language approach to biomimetic design. Artificial Intelligence for Engineering, Design Analysis and Manufacturing 24(4), 507-519.

Shu, L.H., Ueda, K., Chiu, I., \& Cheong, H. (2011). Biologically inspired design. CIRP Annals-Manufacturing Technology 60(2) 673-693.

Snyder, A., Mitchell, K., Bossomaier, T., \& Pallier, G. (2004). The creativity quotient: an objective scoring of ideational fluency. Creativity Research Journal 16(4), 415-420.

Solomon, J. (1986). Children's explanations. Oxford Review of Education 12(1), 41-51.

Thiele, R.B., \& Treagust, D.F. (1994). An interpretive examination of high school chemistry teachers' analogical explanations. Journal of Research in Science Teaching 31(3), 227-242.

Treagust, D.F., Duit, R., Joslin, P., \& Lindauer, I. (1992). Science teachers' use of analogies: observations from classroom practice. International Journal of Science Education 14(4), 412-422.

Zeitoun, H.H. (1984). Teaching scientific analogies: a proposed model. $R e$ search in Science and Technological Education 2(2), 107-205.

Amanda Chou is an MASc candidate in mechanical and industrial engineering at the University of Toronto, where she 
completed her undergraduate degree in engineering science: infrastructure. Her interests are natural language processing and its applications in product design.

L.H. Shu is a Professor of mechanical engineering at the University of Toronto. She received her SM and PhD degrees in mechanical engineering from the Massachusetts Institute of
Technology. Dr. Shu is a Fellow of the CIRP (International Academy of Production Engineering) and has taken leadership roles in the Design Society and the American Society of Mechanical Engineers Design Theory and Methodology Committee.

\section{APPENDIX A}

Examples of "good" analogies for design course topics

\begin{tabular}{|c|c|c|c|}
\hline Topic & Good Analogy Example & Topic & Good Analogy Example \\
\hline Needs identification & $\begin{array}{l}\text { River flow measurement } \rightarrow \text { use of various } \\
\text { methods } \rightarrow \text { standing in river with flowmeter } \\
\text { and taking care to stand far enough away so } \\
\text { as not to interfere flow, but could be some } \\
\text { interference still; launching a free flowing } \\
\text { device and measuring/receiving telemetry } \\
\text { from outside the river }\end{array}$ & Concept generation & $\begin{array}{l}\text { Tree seeds; it benefits a tree to form as many } \\
\text { seeds as possible. Not all may sprout and } \\
\text { many seedlings may die } \rightarrow \text { practically } \\
\text { infeasible design, high cost. But at least the } \\
\text { probability of several with favorable } \\
\text { conditions can become a tree } \rightarrow \text { be suitable } \\
\text { for development. }\end{array}$ \\
\hline Lead users & $\begin{array}{l}\text { Creator of Facebook intention was to connect to } \\
\text { his friends and share pictures, but now } \\
\text { Facebook is used to market businesses } \\
\text { products, to start a cultural political } \\
\text { revolution in some countries, or as a user data } \\
\text { collection system for advertising agencies. }\end{array}$ & Design for assembly & $\begin{array}{l}\text { DFA vs. meal preparation: can come up with } \\
\text { recommendation for customized parts/prefab } \\
\text { that reduce work (can purchase prewashed/ } \\
\text { precut ingredients to reduce work); slim } \\
\text { down number of parts to what is functionally } \\
\text { required (e.g., camping, functionally required } \\
\text { to only heat food, so reduce other parts; } \\
\text { blender, other kitchen appliances) }\end{array}$ \\
\hline Function & $\begin{array}{l}\text { The benefit of identifying/decomposing } \\
\text { functions in a football analogy would be the } \\
\text { coach organizing and planning strategies } \\
\text { with the attackers and defenders on the team } \\
\text { to achieve those objectives. For example, the } \\
\text { positioning of the defenders would be the } \\
\text { "form" to achieve the "function" of } \\
\text { preventing opponents scoring }\end{array}$ & Concept evaluation & $\begin{array}{l}\text { Strategizing a game play where a football coach } \\
\text { will analyze each play against the defense } \\
\text { (player value and placement) of the opposing } \\
\text { team to pick the best option. Analyze each } \\
\text { attacking play } \rightarrow \text { available concepts; defense } \\
\text { value } \rightarrow \text { weight on each option; pick the best } \\
\text { option } \rightarrow \text { concept selection }\end{array}$ \\
\hline Affordances & $\begin{array}{l}\text { Affordance is like how bees spread pollen for } \\
\text { different flowers, while their main function is } \\
\text { otherwise, flowers create large tops to } \\
\text { accommodate that }\end{array}$ & $\begin{array}{l}\text { Modular } \\
\text { architecture }\end{array}$ & $\begin{array}{l}\text { Dressing up in a top piece and a bottom piece } \\
\text { instead of putting on an overall outfit! Makes } \\
\text { it easier to mix and match, or change } \\
\text { following a wardrobe accident! }\end{array}$ \\
\hline Fixation & $\begin{array}{l}\text { Fixation is just like "fanboyism." For example, } \\
\text { Apple lovers just buy Apple stuff and } \\
\text { immediately discredit other brands even } \\
\text { though those might meet their needs more. }\end{array}$ & $\begin{array}{l}\text { Picking unfamiliar } \\
\text { analogies }\end{array}$ & $\begin{array}{l}\text { A boxer practicing on a punching bag vs. } \\
\text { fighting his/her opponent; practicing on a } \\
\text { punching bag } \rightarrow \text { familiar; fighting opponent } \\
\rightarrow \text { unfamiliar } \rightarrow \text { teaches new lesson, new } \\
\text { fighting tactics } \rightarrow \text { generates new concepts }\end{array}$ \\
\hline
\end{tabular}




\section{APPENDIX B}

Selected excerpts from comments on analogy generation and analogy definitions

\begin{tabular}{|c|c|}
\hline & $\begin{array}{l}\text { Partic. } 1 \text { Avg. Analogy } \\
\text { Score }=3.10 / 4.00\end{array}$ \\
\hline Comments & $\begin{array}{l}\text { Regarding the analogies, I did not go for } \\
\text { the quantity. I was more focused on } \\
\text { exploring the concept with a specific } \\
\text { analogy that I had in mind. In my } \\
\text { opinion, an effective analogy is the one } \\
\text { that not only is clearly related to the } \\
\text { concept but it can also be used with } \\
\text { less effort. }\end{array}$ \\
\hline
\end{tabular}

Definition of analogy

A statement that relates two different concepts that are not "literally" or "physically" related, but the founding purpose or essence of the two concepts is the same.
Partic. 2 Avg. Analogy

Score $=3.03 / 4.00$
Partic. 3 Avg. Analogy

Score $=3.42 / 4.00$
Personally found analogies hard to come by for major concepts and felt like most were "examples." Good analogy is like a good cheat sheet, you will always go back to it when needed. I feel like analogies are very experience and mood dependent for most of us doing them in class; good ones should not be fully experience dependent and encompass as much as possible. Distinguishing between positive and negative analogies was quite helpful, a good indication to what is most important in the concept.

A series of statements that define a concept/another statement by providing parallel explanations or concepts that are similar to the positive or negative attributes with the original concept.
Partic. 4 Avg. Analogy Score $=2.29 / 4.00$
Write down anything that came to mind. "No judgment" policy. Good analogy $\rightarrow$ easy to understand $\rightarrow$ not too specific, in-depth knowledge $\rightarrow$ level of novelty $\rightarrow$ not the "go to" analogy.

Definition of analogy

Mapping new concept to easy to understand and relatable idea/concept/ etc. to better comprehend new concept or generate inspiration; drawing inspiration and comprehension from unrelated concepts and phenomena.

Usually wasn't able to think of more than two or three apt analogies, so just tried to work/develop those initial "areas" of thought until they matched somewhat the taught concept. The better analogies were the ones with a possible wider perspective, so there was potential to grasp other related details related to the main concept/ analogy.

A way of explaining a concept/item by describing an analogous or similar one from a different setting that audience may be better able to grasp.

$$
\begin{gathered}
\text { Partic. } 6 \text { Avg. Analogy } \\
\text { Score }=2.53 / 4.00
\end{gathered}
$$

Mapping the element of the source problem you're trying to understand, into element of a known target/concept with which there is an established connection and understanding.
I'd try to think of the concept in other areas of my life and try to remember events that would convey the main meaning. Sometimes writing down a good analogy helps in creating even more analogies. A good analogy for me was something that came out of my daily life. Something that was easy and effortless to connect to intellectually and emotionally.
I thought of a personal experience the topic being studied reminded me of; find context or other stories revolved around topic or person; analogy was developed in my mind; check if it worked in other contexts. Good analogy relates to human experience rather than technical; drives on emotion. Also, sometimes I concentrate on one of the random thoughts in my head or a random emotion that was strongest that day.

Analogy is the simplest way to explain a technical/complex idea/thought/ theory. 